\title{
INFLUENCE OF BREAKDOWN AND LIMITED REPAIR CAPACITY ON THE PERFORMANCE OF A CONTINUOUS PRODUCTION SYSTEM
}

\author{
Pieter Wartenhorst \\ McKinsey \& Company, Amsterdam, NL
}

The influence of machine breakdown on the performance of continuous production- (or service-) systems is often not well understood or not taken into account at all. However, the performance of a system may be heavily affected by machine breakdown, and limited repair capacity. The overall production capacity will be affected, but also severe build-up of jobs may occur at a broken machine. Similar phenomena occur in the area of computer and communication systems, where failure and repair of processors have a major impact on the flow of jobs that have to be handled by those processors.

We present a queueing model that can be used to study such influences. The model consists of $N$ single server queueing stations, each serving its own stream of customers (jobs). The servers (machines or processors) of the $N$ stations are subject to breakdown. Broken servers are repaired by a joint repair facility consisting of $K$ parallel repairmen. Whenever $K<N$, this repair facility is causing interference between the $N$ stations.

We present both an exact (matrix-geometric) solution, and a simple approximation (employing stochastic decompostitions) of the distribution of the queue length at a particular station. With this model various design issues can be investigated such as the number of repairmen that is needed to maintain a pool of machines, or the number of machines that can be assigned to a certain crew of repairmen. Several numerical examples illustrate the approach. 